\begin{tabular}{|c|c|c|}
\hline \multirow{4}{*}{$\begin{array}{r}\text { Case Reports in } \\
\text { Gastroenterology }\end{array}$} & \multirow{2}{*}{\multicolumn{2}{|c|}{ Case Rep Gastroenterol 2013;7:347-351 }} \\
\hline & & \\
\hline & $\begin{array}{l}\text { DOI: 10.1159/000354789 } \\
\text { Published online: August 17, } 2013\end{array}$ & $\begin{array}{l}\text { (c) } 2013 \text { S. Karger AG, Basel } \\
1662-0631 / 13 / 0072-0347 \$ 38.00 / 0 \\
\text { www.karger.com/crg }\end{array}$ \\
\hline & \multicolumn{2}{|c|}{$\begin{array}{l}\text { This is an Open Access article licensed under the terms of the Creative Commons } \\
\text { Attribution-NonCommercial } 3.0 \text { Unported license (CC BY-NC) (www.karger.com/OA- } \\
\text { license), applicable to the online version of the article only. Distribution permitted for non- } \\
\text { commercial purposes only. }\end{array}$} \\
\hline
\end{tabular}

\title{
A Phrygian Cap
}

\author{
Marie-Janne S. van Kamp Donald E. Bouman Pascal Steenvoorde \\ Joost M. Klaase
}

Medisch Spectrum Twente, Enschede, The Netherlands

\section{Key Words}

Gallbladder abnormalities · Congenital anomaly · Gallbladder imaging · Cholecystectomy

\begin{abstract}
A Phrygian cap is a congenital anomaly of the gallbladder with an incidence of $4 \%$. It can simulate a mass in the liver during hepatobiliary imaging and is sometimes mistaken for pathology. A Phrygian cap, however, has no pathological significance and normally causes no symptoms. A case will be presented where a Phrygian cap was found by coincidence during surgery. The patient was operated for colon cancer with liver metastasis in segment V. He underwent a simultaneous right hemicolectomy and wedge resection of the liver lesion. During perioperative inspection, a gallbladder with a folded fundus was seen. This deformity was, in retrospective, detected on the preoperative MRI scan. The patient underwent cholecystectomy to make the wedge resection easier to perform. Otherwise, cholecystectomy for a Phrygian cap is only indicated in case of symptoms. Radiographic imaging can be helpful in narrowing the differential diagnosis. To our knowledge, there is no recent literature about the Phrygian cap and its imaging aspects. Nowadays, multiphase MRI, or multiphase $C T$ in case of MRI contraindication, are the first choices of hepatobiliary imaging.
\end{abstract}

(C) 2013 S. Karger AG, Basel

\section{Introduction}

The gallbladder is a pear-shaped organ and stores bile. Normally, the gallbladder is about $7 \mathrm{~cm}$ long and $3 \mathrm{~cm}$ wide and is located on the undersurface of the liver. Since the introduction of cholecystectomy in 1882 [1], many gallbladder variations are known. These variations include anomalies of form, location or number of gallbladders. Gallbladder anomalies arise from changes in embryological development. During the fourth week of gestation, the liver, gallbladder and biliary tree arise as a ventral bud from the most caudal part of the foregut $[2,3]$. The original hepatic diverticulum differentiates caudally into the

M.J.S. van Kamp

Department of Surgery, Medisch Spectrum Twente

Postbus 50000

NL-7500 KA Enschede (The Netherlands)

E-Mail m.vankamp@mst.nl 
gallbladder [3]. A folding of the fundus during embryological development causes a so-called Phrygian cap. A Phrygian cap is a congenital abnormality of the gallbladder $[4,5]$ and has an incidence of 4\% [6]. It is the most common congenital anomaly of the gallbladder and can simulate a mass in the liver during hepatobiliary imaging [5], which may suggest a tumour. It can also simulate a duplication of the gallbladder [7]. A Phrygian cap, however, has no pathological significance. It is therefore important to use proper imaging techniques to differentiate between a Phrygian cap and other diagnoses.

We report the case of an elderly patient with sporadic pain in the right upper abdominal quadrant and discuss the imaging aspects and treatment of a Phrygian cap.

\section{Case Report}

An 81-year-old man visited the gastroenterologist because he had been suffering from iron deficiency anaemia without obvious blood loss for a few months. Apart from intermittent pain in the right upper abdominal region, there were no other symptoms. His weight remained constant and he did not lose his appetite. Defecation was regular, once a day. His medical record consisted of diabetes mellitus type II, hypertension, impaired renal function and an ear operation many years before. He had no history of gastrointestinal problems. Family history revealed two brothers who had died of colorectal cancer at old age. With a body mass index of 28 he was overweight. Examination of the abdomen did not reveal any unusual findings. No abnormality was palpated during digital rectal examination. A complete blood count revealed anaemia ( $\mathrm{Hb} 6.7 \mathrm{mmol} / \mathrm{l})$ and iron deficiency $(9 \mu \mathrm{mol} / \mathrm{l})$.

The patient underwent colonoscopy. Diverticulosis was seen in the sigmoid. Three polyps were removed during the colonoscopy. A bleeding tumour was found in the ascending colon, $80 \mathrm{~cm}$ from the anal sphincter. Definitive pathology revealed an adenocarcinoma in the ascending colon. An abdominal CT scan confirmed the presence of a process in the ascending colon. It also showed a liver lesion with a diameter of $9 \mathrm{~mm}$, suspicious of liver metastasis. The CT scan did not reveal any other unusual findings. Ultrasonography of the upper abdomen confirmed a liver lesion, with a diameter of $13 \mathrm{~mm}$, suspicious of liver metastasis with an atypical hepatic haemangioma in the differential diagnosis. MRI scan showed a liver lesion in segment $\mathrm{V}$, suspicious of liver metastasis.

The patient underwent simultaneous right hemicolectomy and wedge resection of the liver lesion. During perioperative inspection of the upper abdomen, a gallbladder deformity was seen (fig. 1). The fundus of the gallbladder was folded like a cap. The patient underwent cholecystectomy to make the wedge resection of the liver metastasis in segment $\mathrm{V}$ easier to perform. The surgery proceeded without complications. Pathological examination confirmed the presence of both an adenocarcinoma in the ascending colon and a liver metastasis. There were slight inflammatory changes in the gallbladder, but it did not show stones or a tumour. The patient recovered from surgery without any problems and was discharged after 12 days. The deformity of the gallbladder was, in retrospective, detected on the preoperative MRI scan (fig. 2).

\section{Discussion}

The folded fundus deformity is called a Phrygian cap. It is the commonest congenital abnormality of the gallbladder [4,5]. This anatomical variation was first described by Boyden in 1935 [8]. He named the deformity after the Phrygian cap, an ancient conical cap with 
the top pulled forward (fig. 3). This cap is associated in antiquity with the inhabitants of Phrygia, a region what is now called central Turkey.

A Phrygian cap is a benign anatomical abnormality and normally causes no symptoms. Sometimes patients complain of pain in the right upper quadrant of the abdomen. The Phrygian cap is of no clinical importance other than to not mistake it for pathology.

A Phrygian cap can be identified with ultrasonography, CT scan, oral cholecystography, cholescintigraphy [9] and nowadays also by multiphase MRI. CT and ultrasonography are not always conclusive. According to Meilstrup et al. [9] and Smergel and Maurer [10], delayed imaging by cholescintigraphy is then needed to identify the Phrygian cap because it can show delayed filling of a portion of the gallbladder during hepatobiliary imaging. On cholescintigraphy, the gallbladder appears often smaller than the gallbladder fossa. This finding might suggest a mass lesion in the liver [5]. When the gallbladder shows filling after a couple of hours, a mass lesion can be excluded [7].

The literature about imaging techniques of the Phrygian cap is outdated. Nowadays, multiphase MRI, or multiphase CT in case of MRI contraindication, is the first choice of hepatobiliary imaging. The multiphase images obtained by MRI or CT can usually differentiate between a mass lesion in the liver or gallbladder and a gallbladder anomaly. In our case, this deformity was, in retrospective, detected on the preoperative MRI scan.

Since a Phrygian cap has no pathological significance, prophylactic cholecystectomy is not necessary. Cholecystectomy is indicated in case of symptoms [10] or for other reasons such as wedge resection of the liver, as mentioned in our case report.

In conclusion, when the gallbladder appears smaller than the gallbladder fossa or a mass is seen in the fundus on hepatobiliary imaging, a Phrygian cap should be in the differential diagnosis. Multiphase images by MRI or CT scan should be obtained to exclude a tumour mass.

\section{Author Contributions}

M.J.S. van Kamp: first author. D.E. Bouman: co-author, provided images. P. Steenvoorde: co-author. J.M. Klaase: co-author, supervisor.

\section{Disclosure Statement}

The authors declare that they have no conflict of interest.

\section{References}

1 Hardy KJ: Carl Langenbuch and the Lazarus Hospital: events and circumstances surrounding the first cholecystectomy. Aust N Z J Surg 1993;63:56-64.

$\rightarrow 2$ Severn CB: A morphological study of the development of the human liver. 1. Development of the hepatic diverticulum. Am J Anat 1971;131:133-158.

3 Rappaport AM, Wanless IR: Diseases of the Liver, ed 7. Philadelphia, Lippincott, 1993, p 1.

4 De Csepel J, Carroccio A, Pomp A: Soft-tissue images. 'Phrygian cap' gallbladder. Can J Surg 2003;46:50-51.

-5 Lamah M, Karanjia ND, Dickson GH: Anatomical variations of the extrahepatic biliary tree: review of the world literature. Clin Anat 2001;14:167-172.

6 Edell S: A comparison of the Phrygian cap deformity with bistable and gray scale ultrasound. J Clin Ultrasound 1978;6:34-35.

7 Dalal S, Chauhan TS, Kumar R, Choudhury SR: Pseudo-duplication of the gall bladder due to Phrygian cap a case report. Internet J Surg 2013;29. 


\section{Case Reports in
Gastroenterology}

\begin{tabular}{l|l}
\hline Case Rep Gastroenterol 2013;7:347-351 \\
\hline DOI: $10.1159 / 000354789$ & $\begin{array}{l}\text { @ 2013 S. Karger AG, Basel } \\
\text { www.karger.com/crg }\end{array}$ \\
\hline
\end{tabular}

van Kamp et al:: A Phrygian Cap

8 Boyden EA: The Phrygian cap in cholecystography: a congenital anomaly of the gallbladder. Am J Radiol 1935;33:589.

-9 Meilstrup JW, Hopper KD, Thime GA: Imaging of gallbladder variants. AJR Am J Roentgenol 1991;157: 1205-1208.

10 Smergel EM, Maurer AH: Phrygian cap simulating mass lesion in hepatobiliary scintigraphy. Clin Nucl Med 1984;9:131-133.

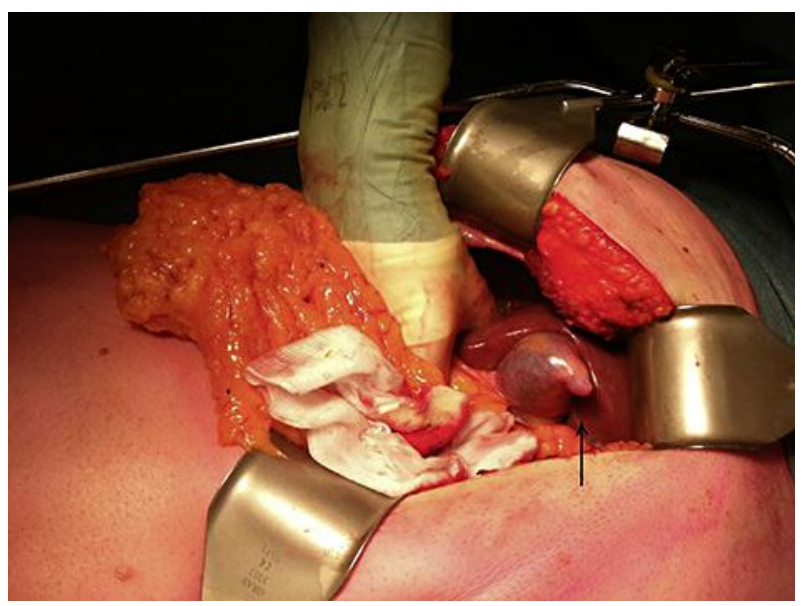

Fig. 1. Perioperative photograph of the gallbladder. The fundus of the gallbladder is folded like a cap (arrow).

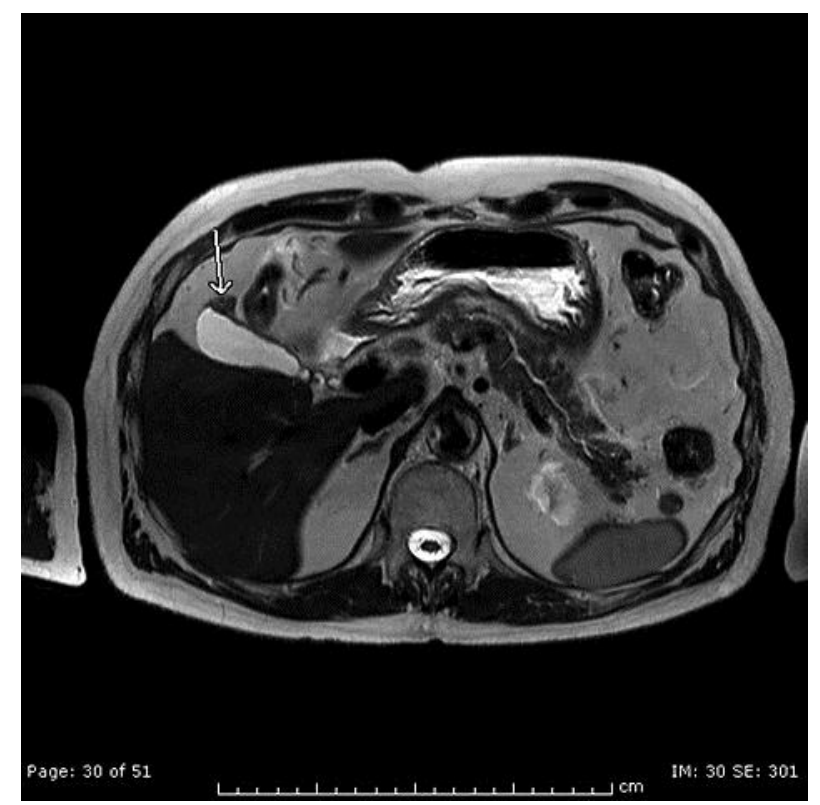

Fig. 2. T2-weighted preoperative MRI of the liver showing a hypo-intensity on the ventral side of the gallbladder (arrow). This hypo-intensity is caused by the Phrygian cap and was seen on the MRI in retrospect. 


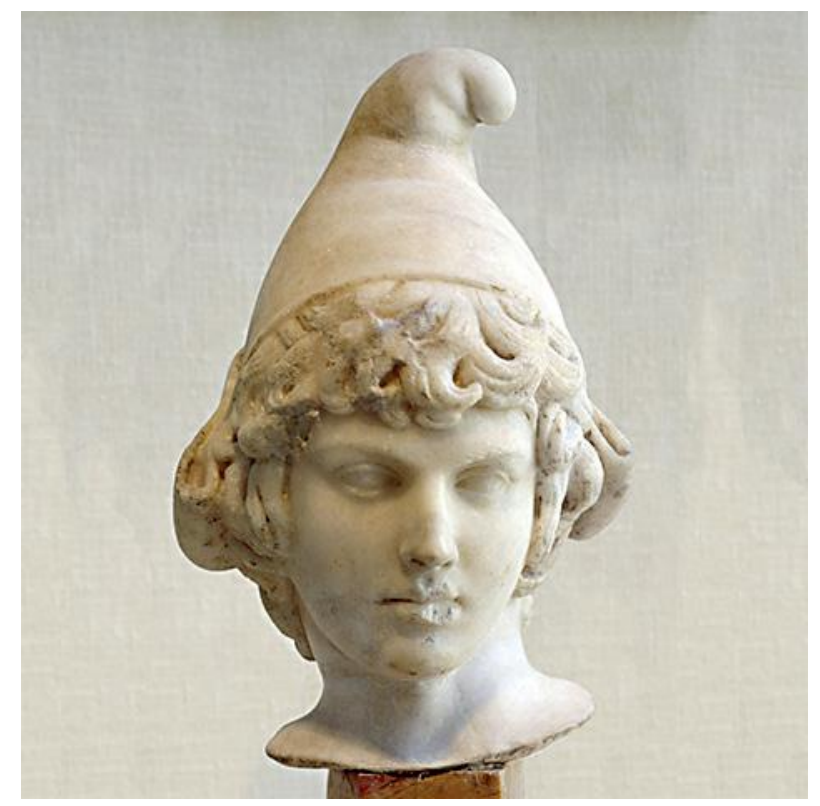

Fig. 3. This statue wears a conical headdress which fits closely around the head and is characterized by the top pulled forward. This cap is associated in antiquity with the inhabitants of former Phrygia. 